dauerhafter Frieden im südlichen Afrika ohne eine Reform der Apartheid nicht erreicht werden kann. - In der Hauptsache jedoch bestätigt dieser Gang der Ereignisse den Wert der Arbeit Kühnes in ihrem Bemühen, die sowjetische Afrikapolitik nüchtern zu betrachten, die Methoden ihrer Einflußsuche herauszuarbeiten und den geopolitisch untergeordneten Stellenwert ihrer Politik in Afrika, der auch eine niedrige Risikobereitschaft bedingt, herauszuarbeiten.

Peter Meyns

\title{
Marcus Franda
}

\section{The Seychelles. Unquiet Islands}

Profiles - Nations of Contemporary Africa, Westview Press, Boulder, Colorado; Gower, Hampshire, England; 1982, XIII, 140 S., US $\$ 19.50$

Die im Indischen Ozean gelegene Inselgruppe - nach Bevölkerungszahl und Gebietsgröße einer der kleinsten Staaten der Welt - ruft hierzulande Gedanken an paradiesische Strände, vielleicht noch an häufige Putschversuche hervor. Das wissenschaftliche Schrifttum zwängt die seit 1976 unabhängige frühere britische Kolonie gern in das Raster vom durch Klassen- und Rassengegensätze geprägten Kleinstaat, dessen von der Bevölkerungsmehrheit gestützter sozialistischer Präsident - hier heißt er René - sich wacker um interne Wohlfahrt und externe Blockfreiheit bemüht. Die Wirklichkeit sieht differenzierter aus.

Die Seychellen sind ein Staat, der nicht genug Ressourcen besitzt, um allein lebensfähig zu sein, der überdies nicht über ausreichende Finanzkraft und Technologie verfügt, um die vorhandenen Ressourcen, etwa die Fischbestände, auszuschöpfen, ja nicht einmal, um diese gegen fremden Zugriff zu verteidigen - was sich insbesondere sowjetische und japanische Fischereiflotten zunutzemachen. Ausbildungsmöglichkeiten und Arbeitsplätze sind gering. Die vorkoloniale Elite transferierte ihre Gewinne größtenteils ins Ausland. Nach der von dem heutigen Präsidenten René durch geschicktes Taktieren, durch Mobilisierung auch von UNO und OAU erzwungenen Unabhängigkeit von Großbritannien, stürzte der erste Präsident, James Mancham (zunächst ein Gegner der Unabhängigkeit), das Land in das Abenteuer der Abhängigkeit von westlichen Tourismus-Investoren. Die Seychellen drohten zum Jet-Set-El-Dorado zu verkommen, mit Konsequenzen im sozialen, kulturellen und ökologischen Bereich. Mit tanzanischer Hilfe stürzte René 1977 den Playboy Mancham und propagierte eine sozialistische Neuorientierung. Er erzielte Erfolge im Gesundheitswesen und im Ausbildungsbereich, er stoppte die alleinige Ausrichtung auf den Tourismus. Drängende Probleme aber blieben ungelöst oder verschlimmerten sich: ineffektive Verwaltung, Planungsfehler, Gängelung kleiner Gewerbetreibender durch Bürokratismus, fühlbare Beschneidung der Meinungsfreiheit. Alles dies hat zur Entwicklung eines starken umstürzlerischen Potentials geführt, auf das 
der Staat mit schärferer Repression reagierte. Die Lösung der inneren Probleme erscheint als Voraussetzung für die Abwehr ausländischer Begehrlichkeiten und die Fernhaltung der alten Eliten um den in London exilierten Mancham, der allerdings noch starke Sympathien in der Bevölkerung genießt. Je fühlbarer die Widersprüche zwischen sozialistischer Rhetorik und Minimierung individueller Entfaltungschancen werden, desto bedrohter ist Renés Herrschaft.

Frandas Buch zeichnet ein Bild von den Seychellen, das die vorstehend beschriebene Situation deutlich hervortreten läßt. Ohne theoretische Voreingenommenheit nennt er die Probleme beim Namem, freilich im Hinblick auf die innenpolitische Lage, vor allem: die Konkurrenten Renés im eigenen Lager, nicht immer mit der wünschenswerten Klarheit. Einem historischen Abriß folgen sozio-kulturelle Grunddaten, eine Schilderung der postkolonialen Entwicklung, die Beschreibung der Wirtschaftslage und ein Schlußkapitel "Change", das Bilanz zieht und Perspektiven diskutiert. Dabei wird dem Spannungsverhältnis zwischen Tourismus und Schutz des (auf den Seychellen äußerst verletzlichen) Ókosystems ebenso Raum gegeben wie der Rolle der Seychellen auf dem Schachbrett der beiden Supermächte: Die Geographie weckt hier Aspirationen, gibt der Regierung aber auch Chancen.

Geschichte und Zukunft der Seychellen machen das Schicksal des winzigen Staates zu einem Exempel, an dem vieles über Grundbedingungen heutiger internationaler Beziehungen und der in ihrem Rahmem möglichen Entwicklungschancen studiert werden kann. Marcus Franda hat das Material dazu knapp, aber in fairer und verläßlicher Weise aufbereitet. Daß ein schmales Buch dieser Art derart viel Geld kosten muß, steht auf einem anderen Blatt.

Philip Kunig

\section{Reinhard Bodemeyer}

Administration for Development - The Effects of Decentralization on District Development in Zambia

Materialien des Zentrums für regionale Entwicklungsforschung der Justus-Liebig-Universität Gießen, Band 5, Gießen, 1984, X und 104 S.

Die Schrift Bodemeyers reiht sich ein in eine Vielzahl praxisorientierter Untersuchungen, die in den letzten Jahren zu Fragen der Entwicklungsländer erschienen sind. Der überwiegende Teil der Arbeit gilt der empirischen Analyse der Umsetzung der 1980 gesetzlich verordneten Dezentralisierung im Mkushi District. Das Herausgreifen eines exemplarischen Beispiels gibt einen tiefen Einbilck in die Probleme der Dezentralisierung eines unitarischen Einparteienstaates, der die Analyse anderer dezentraler Systeme in vergleichbaren Staaten erleichtern mag. 